\title{
A importância do exame de imagem, ultrassonografia, para o rastreamento de preenchedores faciais - caso clínico
}

The importance of ultrasound imaging for the tracking of facial fillers - clinical case

La importancia de la ecografía para el seguimiento de los rellenos faciales - caso clínico

\author{
Alessandro Ítalo Cruz \\ ORCID: https://orcid.org/0000-0003-4679-7302 \\ Centro Universitário Tiradentes, Brasil \\ E-mail: Aleitalocruz@gmail.com \\ Erica Limeira Rocha \\ ORCID: https://orcid.org/0000-0002-7102-5534 \\ Centro Universitário Tiradentes, Brasil \\ E-mail: Erika.rr@hotmail.com \\ Joedy Maria Costa Santa Rosa Lima \\ ORCID: https://orcid.org/0000-0001-8486-0128 \\ Centro Universitário Tiradentes, Brasil \\ E-mail: joedysantarosa@hotmail.com \\ Lays Adrielle Ferreira Catum \\ ORCID: https://orcid.org/0000-0001-6607-2929 \\ Centro Universitário Tiradentes, Brasil \\ E-mail: laysferreiira29@gmail.com \\ Palmyra Catarina Costa Santa Rosa Lima \\ ORCID: https://orcid.org/0000-0002-7017-524X \\ Centro Universitário Tiradentes, Brasil \\ E-mail: drapalmyrasantarosa@gmail.com
}

\begin{abstract}
Resumo
Introdução: É crescente a demanda pela harmonização facial, com a adoção de procedimentos estéticos faciais, por exemplo, a utilização de preenchedores faciais como o silicone, o polimetilmetacrilato (PMMA) e o Ácido hialurônico. No entanto, os profissionais que aplicam estes produtos, devem conhecer bem todos os tipos de preenchedores para que possam prevenir futuros problemas. Da mesma forma, que saiba da importância do exame de ultrassonografia como procedimento primordial para auxiliar na resolução de danos. Objetivo: Apresentar como a ultrassonografia é imprescindível para a aplicação de preenchedores faciais, assim como para tratar efeitos danosos à face em decorrência de complicações. Metodologia: É um estudo de caso de abordagem qualitativa, descritivo, realizado em consultório de Odontologia. Relato de caso: Paciente do sexo feminino, 57 anos de idade, procurou atendimento odontológico para fazer harmonização facial com preenchimento do mento (queixo), um mês depois queixou-se de uma massa globosa na região submentoniana. Conclusão: $\mathrm{O}$ exame de ultrassonografia foi crucial para a confirmação de que o preenchedor facial, o ácido hialurônico não fez deslizamento. Foi identificada, na USG, uma imagem sólida hipoecóica. O conhecimento dos preenchedores faciais assegurou ao profissional descartar a hipótese de migração do ácido hialurônico.
\end{abstract}

Palavras-chave: Estética; Ultrassonografia; Preenchedores faciais.

\begin{abstract}
Introduction: There is a growing demand for facial harmonization, with the adoption of facial aesthetic procedures, for example, the use of facial fillers such as silicone, polymethylmethacrylate (PMMA) and hyaluronic acid. However, professionals who apply these products must know well all types of fillers so that they can prevent future problems. Likewise, let them know about the importance of the ultrasound exam as a primordial procedure to help in the resolution of damages. Objective: To present how ultrasonography is essential for the application of facial fillers, as well as for treating harmful effects to the face due to complications. Methodology: It is a case study with a qualitative, descriptive approach, carried out in a dentistry office. Case report: A 57-year-old female patient sought dental care to perform facial harmonization with filling the chin, one month later she complained of a globular mass in the submental region. Conclusion: The ultrasound examination was crucial to confirm that the facial filler, hyaluronic acid, did not slip. A solid hypoechoic image was identified on the USG. Knowledge of facial fillers assured the professional to discard the hypothesis of hyaluronic acid migration.
\end{abstract}

Keywords: Aesthetics; Ultrasonography; Facial fillers. 


\begin{abstract}
Resumen
Introducción: Existe una demanda creciente de armonización facial, con la adopción de procedimientos de estética facial, por ejemplo, el uso de rellenos faciales como silicona, polimetilmetacrilato (PMMA) y ácido hialurónico. Sin embargo, los profesionales que aplican estos productos deben conocer bien todo tipo de rellenos para que puedan prevenir problemas futuros. Asimismo, infórmeles sobre la importancia de la ecografía como procedimiento primordial para ayudar en la resolución de daños. Objetivo: Presentar cómo la ecografía es fundamental para la aplicación de rellenos faciales, así como para el tratamiento de efectos nocivos en el rostro por complicaciones. Metodología: Es un estudio de caso con abordaje cualitativo descriptivo, realizado en un consultorio de odontología. Caso clínico: Paciente de sexo femenino de 57 años que acude a atención odontológica para realizar armonización facial con relleno de mentón, un mes después se queja de una masa globular en la región submentoniana. Conclusión: El examen ecográfico fue crucial para confirmar que el relleno facial, ácido hialurónico, no se deslizaba. En el USG se identificó una imagen sólida hipoecoica. El conocimiento de los rellenos faciales aseguró al profesional descartar la hipótesis de la migración del ácido hialurónico.
\end{abstract}

Palabras clave: Estética; Ecografía; Rellenos faciales.

\title{
1. Introdução
}

O rejuvenescimento facial não cirúrgico usando produtos químicos como toxina botulínica e ácido hialurônico está ganhando popularidade crescente no aprimoramento da estética facial e seu uso potencial em práticas odontológicas.

O número de procedimentos estéticos faciais minimamente invasivos realizados anualmente continua a aumentar em todo o mundo (Goodman et al., 2020). As injeções de preenchimento nas áreas faciais se tornaram mais conhecidas nos últimos anos devido ao surgimento de novas tecnologias e formulações dos produtos utilizados. No entanto, uma importante precaução com relação ao sistema estomatognático diz respeito ao seu arranjo de estruturas estética e funcionalmente importantes próximas umas das outras (Signorini et al., 2016).

Procedimentos odontológicos realizados nas proximidades de preenchimentos dérmicos podem resultar em complicações dos preenchimentos dérmicos, como infecções que podem mimetizar uma infecção dentária. Essas infecções de preenchimentos dérmicos devem ser diferenciadas da celulite facial ou da infecção dentária, pois o tratamento para infecções de preenchimentos dérmicos pode ser prolongado com o uso repetido de antibióticos, incisão e drenagem ou remoção do próprio material de preenchimento. Os cirurgiões-dentistas precisam estar cientes desse risco potencial para reconhecê-lo e gerenciá-lo de forma adequada (Ramzi et al., 2015).

As crescentes demandas para obter uma estética dentária superior têm desempenhado um papel importante nos últimos anos na melhoria da qualidade dos materiais e técnicas dentais disponíveis. Isso aprimorou a pesquisa para obter materiais odontológicos superiores e incentivou os dentistas a obterem graus mais elevados neste campo cosmético em expansão e a introduzir equipamentos de alta tecnologia em suas práticas odontológicas, a fim de atender às necessidades de seus pacientes (Dalati \& Koussayer, 2020).

A estética facial (não cirúrgica), por outro lado, não recebeu tanta atenção da Odontologia até recentemente, quando produtos químicos como preenchedores de ácido hialurônico e toxina botulínica começaram a ser exigidos pelos pacientes e os fabricantes de Odontologia começaram a torná-los mais disponíveis e incorporou esses materiais em seus catálogos e anúncios (Dalat \& Koussayer, 2020).

Os preenchimentos faciais são materiais sintéticos utilizados nos tecidos moles da face para fins estéticos e representam uma alternativa à cirurgia invasiva. Um preenchimento amplamente utilizado é o ácido hialurônico. Este oferece vários benefícios, incluindo alta biocompatibilidade, propriedades físico-químicas ideais e altos níveis de biossegurança quando injetado corretamente (Attenello \& Maas, 2015).

Os preenchimentos injetáveis são alternativos cada vez mais populares à cirurgia estética incisional para reduzir as rítides faciais. Os preenchimentos aloplásticos podem ser classificados como temporários ou permanentes. O ácido hialurônico 
(AH) é comumente administrado como um preenchimento temporário que desaparece lentamente por meio da degradação enzimática. Enchimentos permanentes usam polimetilmetacrilato (PMMA), entre outros (Limongi et al., 2016).

Os materiais sintéticos de preenchimento mais utilizados no Brasil são: silicone, polimetilmetacrilato (PMMA) e Ácido hialurônico (Christensen, 2005, Broder \& Cohen, 2006).

O aumento dos tecidos moles é um procedimento comum e uma grande variedade de preenchimentos injetáveis são usados. O silicone líquido injetável (LIS) foi o primeiro preenchimento injetável altamente popularizado. LIS é um preenchedor permanente e pode ser usado na correção de sulcos e rugas faciais. Algumas complicações são inerentes ao procedimento e podem resolver espontaneamente, como vermelhidão, inchaço e reações de hipersensibilidade imediata. Reações indesejadas, como granulomas, infecções, oclusão vascular, também podem ocorrer após o tratamento com LIS e podem aparecer vários anos após as injeções (Hexsel \& Morais, 2014).

O uso de PMMA incide em técnicas de preenchimento estético sem cortes, denominada de bioplastia, trata-se de um procedimento minimamente invasivo. Os materiais utilizados para um preenchimento são géis ou suspensões sintéticas injetáveis, com resultados transitórios ou permanentes amplamente popularizados (Jesus, 2011).

Importante entender que o uso crescente do PMMA em procedimentos estéticos se justifica pelo seu baixo custo e facilidade de aplicação, todavia, há inúmeros casos de eventos adversos relativos à aplicação de PMMA em procedimentos estéticos (Dolghi, 2014).

O ácido hialurônico é considerado o preenchimento mais seguro devido em parte ao seu suposto baixo risco de imunogenicidade e às alegações de reversibilidade com hialuronidase. Nos últimos anos, a indústria tem tentado criar produtos mais diferenciados e mais duradouros, modificando a estrutura química dos géis HA (Alcântara et al., 2018).

Os preenchedores de ácido hialurônico são conhecidos por um perfil de segurança confiável, mas ocorrem complicações, como eventos adversos vasculares graves. Embora os avanços tecnológicos tenham tornado os preenchimentos de HA mais insolúveis, resultando em uma meia-vida mais longa, eles ainda são degradados e absorvidos in vivo e podem exibir diferentes padrões de difusão e distribuição ao redor do local de injeção ao longo do tempo (Schelke, Decates \& Velthuis, 2018).

Os preenchimentos de AH têm a vantagem de serem solúveis com hialuronidase em caso de complicações. Se isso for necessário, identificar a localização do preenchimento na pele é importante, pois a hialuronidase deve ser injetada na massa do preenchimento. Porém, quando o preenchimento é colocado profundamente na pele, a detecção pode ser muito difícil (Schelke, Decates \& Velthuis, 2018).

Deste modo, em casos de complicações o uso de ultrassonografia passa a ser um divisor de águas, por ser uma técnica de imagem de alta resolução específica para avaliação de tecidos moles e que pode fornecer uma grande variedade de informações antes, durante e após os procedimentos clínicos. Embora o US da região facial não tenha sido amplamente explorado, ele pode fornecer detalhes importantes para auxiliar no planejamento e execução de procedimentos (Rocha et al., 2020).

O exame de ultrassom pode ser uma ferramenta importante para melhorar a segurança dos tratamentos de preenchimento com ácido hialurônico. A US é uma forma eficaz de avaliar anatomicamente a área de injeção de AH e monitorar a dinâmica do material no tecido circundante. Por meio da US, é possível verificar a localização e a relação entre estruturas importantes, como vasos, músculos e glândulas - que podem influenciar no procedimento de injeção - além de monitorar a movimentação do preenchedor através do tecido (Schelke, Decates \& Velthuis, 2018).

O presente trabalho tem como objetivo apresentar como a ultrassonografia é imprescindível para a aplicação de preenchedores faciais, assim como para tratar efeitos danosos à face em decorrência de complicações. 


\section{Metodologia}

A metodologia empregada neste artigo foi o relato de caso clínico com finalidade descritiva e de abordagem qualitativa. Na pesquisa descritiva realiza-se o estudo, a análise, o registro e a interpretação dos fatos do mundo físico sem a interferência do pesquisador (Barros \& Lehfeld, 2007).

$\mathrm{O}$ estudo de caso considera um fenômeno individual com profundidade para compreender a situação. Tem como característica ser de cunho interpretativo, ao utilizar a descrição, ou avaliativo, empregando a descrição e a interpretação (Marconi \& Lakatos, 2008).

Segundo Pereira et al. (2008) a interpretação do pesquisador é fundamental para articular o conhecimento científico com os casos clínicos.

Ressalta-se que a paciente autorizou a utilização do caso clínico para fins de pesquisa por meio do Termo de Consentimento Livre e Esclarecido (TCLE).

\section{Relato de Caso}

Uma Paciente, chamada L. T. T., 57 anos de idade, procurou atendimento odontológico para fazer harmonização facial com preenchimento do mento (queixo). Foi realizado o preenchimento com ácido hialurônico da marca RENNOVA ULTRA DEEP LIDO, é um volumizador produzido com a inovadora tecnologia Hybrid MoBi ${ }^{\mathrm{TM}}$, tendo sido injetado 1,25 ml, com emprego da agulha supraperiosteal.

O produto é ideal para sulco nasolabial profundo,linhas de marionete profundas, mento, região malar, pontos de sustentação, contorno mandibular e volumização proporcionando uma aparência muito mais jovem em minutos. Possui duas versões, com e sem lidocaína. Segundo a bula da marca, o tempo de duração é de até 12 meses.

Semanas depois, o queixo estava com ótima aparência. Todavia, após um mês a paciente voltou se queixando de existir um caroço pequeno na região submentoniana, isto é, a região da papada, que foi constatada pela apalpação. Isto fez a paciente acreditar que o preenchimento escorreu.Então, a solução teve como procedimento fazer o exame de ultrassonografia para identificar o produto que fez a protuberância naquela região.

Foi realizado o ultrassom da marca Aparelho GE, cuja técnica colocou a paciente em decúbito dorsal com transdutor linear de 7,5 MHz. O laudo da ultrassonografia constatou a ausência de qualquer preenchedor facial na região submentoniana, sendo identificado o ácido hialurônico na região do mento, local onde foi colocado. Portanto, neste caso, não houve falha da aplicação do ácido hialurônico, mas sim um evento distinto da aplicação do preenchedor facial que fez surgir a massa na região submentoniana. 
Figura 1. Harmonização facial com preenchimento do mento.

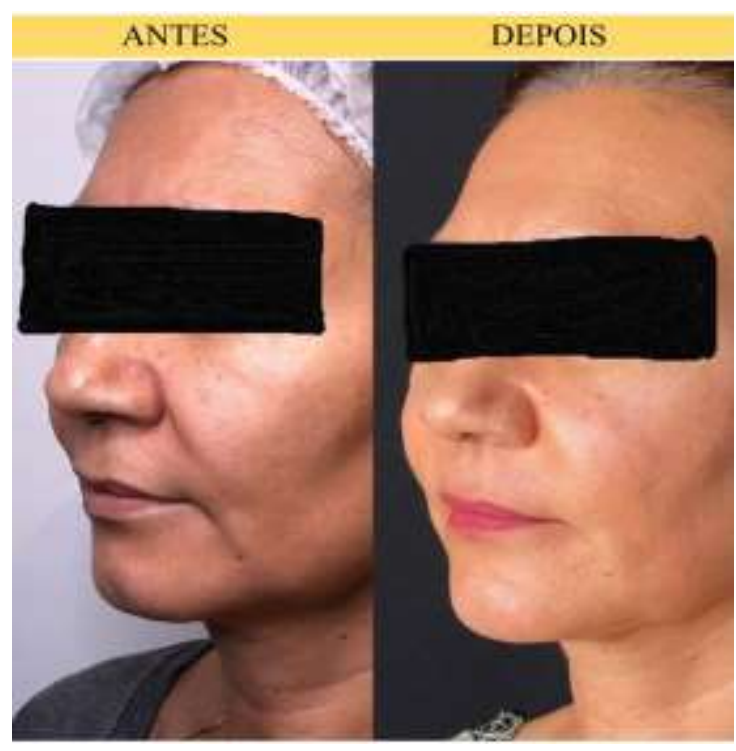

Fonte: Autores.

Pode-se perceber da Figura 1, da paciente L. T. T., que havia uma cova no mento da paciente e que depois do procedimento de preenchimento facial é visível a correção.

A Figura 2 mostra o resultado da ultrassonografia (USG da região cervical com dopller colorido) evidenciando uma imagem sólida hipoecóica que não constitui material de preenchimento facial, isto é, não é o ácido hialurônico.

Figura 2. Imagem da Ultrassom da Região Submentoniana da Sra. L. T. T.
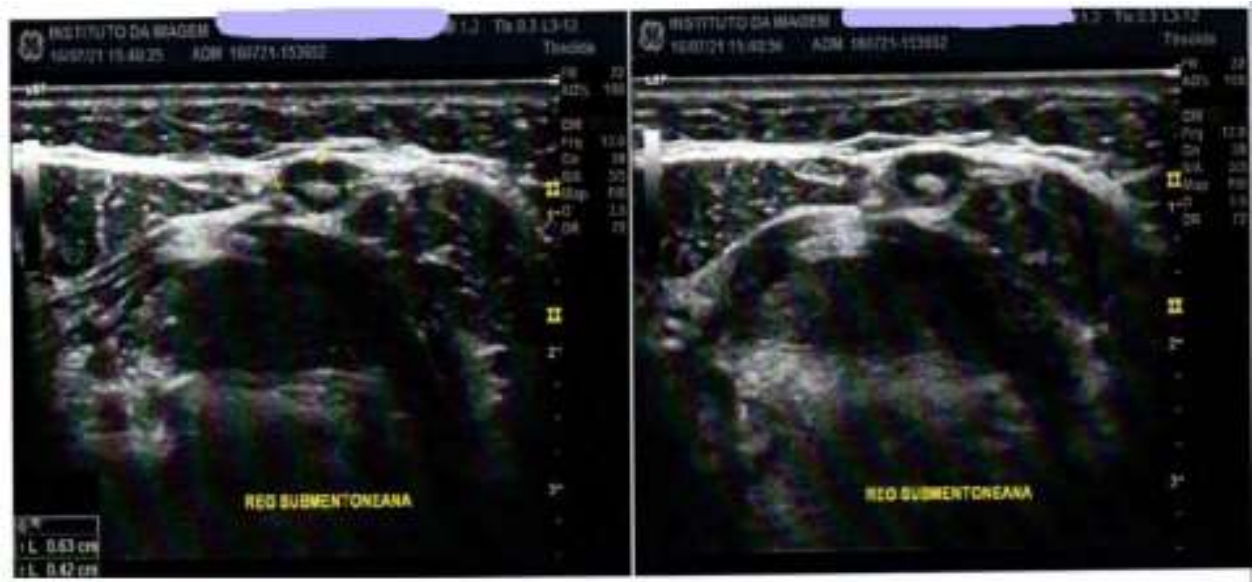

Fonte: Exames da paciente.

\section{Discussão}

Considerando os preenchedores faciais de silicone, PMMA, ácido hialurônico, são apresentadas reflexões quanto aos seus usos e problemas relacionados, como também, aborda-se a utilização da ultrassonografia para o rastreamento de preenchedores faciais como forma de detectar com precisão o tipo de substância injetada, contribuindo para tratamentos de complicações.

Sobre o uso de silicone como preenchedor facial, percebeu-se que o mesmo não pode ser removido depois de injetado, por ter duração permanente, sendo, desta forma, uma condição com sérios riscos. 
As injeções de silicone são muito sensíveis à técnica e requerem uma colocação profunda do produto. Injeções excessivamente superficiais podem resultar em fibrose excessiva, nódulos, estrias, perolização e elevações semelhantes a cicatrizes hipertróficas. No entanto, uma técnica de injeção de gotas em série pode fornecer os melhores resultados estéticos para corrigir linhas finas, rugas e cicatrizes de acne com silicone (Dayan \& Bassichis, 2008).

Como se pode ver as injeções de silicone requer empregar técnica precisa, uma vez que falhas podem produzir complicações importantes na face. Neste mesmo sentido alertam Vargas, Amorim e Pitanguy (2009) em um estudo com 10 pacientes entre 40 e 60 anos de idade, identificaram reação alérgica como manifestação mais prevalente, seguida da deformidade do contorno facial com diminuição da mímica facial.

Como se vê a seguir, o silicone obteve aprovação de uso pela FDA (administração de alimentos e medicamentos dos EUA) para o tratamento de uma patologia ocular, todavia, seu uso na seara cosmética requer cautela e cuidados.

em o óleo de silicone (dimetilsilosano) nem o silicone puro livre foram aprovados pelo FDA para injeção na pele, embora o óleo de silicone tenha sido aprovado para o tratamento de descolamento de retina. O polidimetilsilosano (PDMS1000), uma forma purificada de óleo de silicone, foi supostamente usado off-label nos EUA, como enchimento de tecidos moles e abertamente em outros países para fins cosméticos (Wortsman et al., 2011).

Em se tratando do polimetilmetacrilato (PMMA), no Brasil é empregado para preenchimento subcutâneo e precisa ser registrado na Anvisa, pois é um produto de uso em saúde da classe IV (máximo risco). O produto está autorizado para as seguintes aplicações pela agência nacional de vigilância sanitária (anvisa): correção de lipodistrofia (alteração no organismo que leva à concentração de gordura em algumas partes do corpo) provocada pelo uso de antirretrovirais em pacientes com síndrome da imunodeficiência adquirida (aids); e, correção volumétrica facial e corporal, que é uma forma de tratar alterações, como irregularidades e depressões no corpo, fazendo o preenchimento em áreas afetadas por meio de bioplastia (Brasil, 2018).

Então, há aprovação pela ANVISA quanto ao uso do PMMA para preenchimento facial e tem caráter permanente tal como o silicone. Um ponto benéfico, segundo Vargas, Amorim e Pitanguy (2009) é que não é alergênico, porém depende do veículo utilizado para ser considerado completamente inerte no organismo. Mas, não é o que todos os estudiosos afirmam, segundo Requena et. al. (2011) o PMMA hoje é raramente utilizado devido ao alto risco alergênico associado ao colágeno bovino.

Outra posição teórica contrária à de Vargas, Amorim e Pitanguy (2009) e à aprovação da ANVISA é a de JunkinsHopkins (2015) ao afirmar que o uso do PMMA como preenchedor facial, independentemente da quantidade aplicada, é arriscado, podendo ocorrer reações inflamatórias crônicas, dor crônica, infecções, formação de nódulos, enrijecimento da região, rejeição do organismo e até necrose do tecido. Mais ainda, o risco aumenta conforme a quantidade aplicada, portanto, o volume usado deve seguir o bom senso do médico especialista.

Mas, ainda que exista um risco que parece grave, como mencionado por Junkins-Hopkins (2015), os autores Blanco et al. (2018) relatam que as complicações relacionadas ao PMMA são raras, variando entre 0,01\% a 3\%, e apesar de baixos são dados importantes a considerar, uma vez que há falhas nos registros das complicações, seja pelo fato de serem complicações tardias quanto pela omissão dos fatos em prontuário médico.

O PMMA também foi aprovado para uso cosmético, pela FDA, em 2007, contudo, há riscos como ressaltam Limongi et al. (2016) ao afirmarem que a injeção de PMMA na região periocular pode estar associada à inflamação de células gigantes, nódulos fibróticos, amarelecimento da pele e mau posicionamento das pálpebras. O melhor tratamento para essas complicações da injeção de PMMA permanece incerto. A injeção de corticosteroide pode ter eficácia limitada, enquanto a citorredução cirúrgica pode ser benéfica. Uma investigação mais aprofundada pode esclarecer os melhores protocolos de tratamento para os efeitos colaterais das injeções de PMMA na face média.

Apesar das incertezas no tratamento das complicações com o uso de PMMA, os estudos de Dayan \& Bassichis (2008) apontam uma certeza, afirmam que as esferas de PMMA fornecem correção permanente, pois o colágeno bovino é substituído 
em 3 meses pelo tecido conjuntivo do hospedeiro. Após 7 meses, foi demonstrado que há muitas poucas diferenças entre as fibras de colágeno ao redor do implante e aquelas do tecido conjuntivo circundante. A taxa de complicações foi de $7 \%$, sendo a formação de nódulos no lábio o problema mais comumente relatado.

Segundo Dolghi (2014) as esferas de PMMA são de 50 micrômeros $(\mu \mathrm{m})$ de diâmetro, portanto, não permite que os macrófagos do organismo humano realizem fagocitose nem reabsorção destes compostos injetáveis, fato que mantém o produto no local implantado. Da mesma forma, cada versão de AH tem um tamanho de partículas de gel diferente, sendo distintas entre

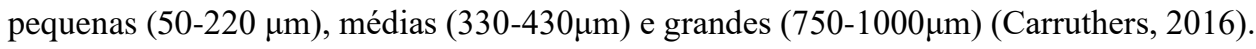

Enquanto que Badin (2005) diz que as microesferas sintéticas de PMMA têm diâmetro entre 40 e 60 mm, veiculadas em um meio de suspensão que pode ser colágeno, aproteico ou cristalóide, isto é, muito maiores que os micrômeros citados por Dolghi (2014).

Entende-se, então, como o PMMA sugere ser um seguro preenchedor facial, pois foi aprovado pela FDA e ANVISA, como também se mantém no organismo humano sem sofrer decomposição e, por conta do componente colágeno bovino promove maior similaridade com a pele humana.

Diante do exposto, pode-se deduzir que o uso de PMMA como preenchedor facial mostrou-se, esteticamente, mais promissor em relação às complicações e até mais seguro que o uso de silicone.

Em se tratando da aplicação do ácido hialurônico são apontadas como principais vantagens do preenchimento dérmico: biocompatibilidade, substância absorvível, baixo risco de alergia, não é carcinogênico, estimula a síntese do colágeno, restaura a hidratação profunda da pele, baixa imunogenicidade, muitos dados publicados sobre seu uso na prática clínica, procedimento quase indolor, resultado imediato e duradouro, aplicação do produto pode ser revertida através do uso da hialuronidase (Monteiro 2010; Maia \& Salvi 2018; Morais et al., 2017); importante salientar que os resultados são imediatos e duram de 6 a 18 meses, sendo reversível (Dayan \& Bassichis, 2008).

Outros pesquisadores como Bertossi et. al. (2019) assinalam para uma durabilidade reduzida da aplicação do AH com efeitos, justificando que variando entre 7-12 meses, isto é, 6 meses a menos do que defende Dayan \& Bassichis, 2008. Imporante, também, é que essa durabilidade depende do grau de ligação cruzada e das características individuais dos sujeitos (Bertossi et. al, 2019).

De outro modo, há o risco de reações adversas decorrente da aplicação do ácido hialurônico, por exemplo, inflamação local, hiperemia, sensibilidade, hematomas, eritemas transitórios, edema localizado, efeito "Tyndall" (uma coloração azulada no local da aplicação) (Crocco et al. 2012; Parada et al. 2016).

Mas, essas reações adversas, segundo os pesquisadores Gladstone \& Cohen, 2007; Sattler \& Gout (2017), só ocorrem devido à aplicação superficial do produto.

Mais estudos que incluem histologia, ultrassom e teste cutâneo são de suma importância para entender melhor os mecanismos pelos quais diferentes preenchimentos de $\mathrm{AH}$ podem produzir respostas variáveis nos sujeitos. $\mathrm{O}$ conhecimento desses dados pode ajudar a realizar os tratamentos com segurança e gerenciar corretamente as complicações posteriores.

Importante apresentar alguns prós e contras sobre os preenchedores silicone, PMMA e ácido hialurônico. A Tabela 1 sintetiza as funções, usos, prós, contras e comentários. 
Tabela 1. Preenchedores faciais.

\begin{tabular}{|c|c|c|c|c|c|}
\hline Preenchedores & Função & Uso & Prós & Contras & Comentários \\
\hline $\begin{array}{lr}\text { Silicone } & \text { (Silikon } \\
1000 \text { e } & \text { Adaptosil } \\
5000) & \end{array}$ & $\begin{array}{l}\text { Óleo de silicone } \\
\text { altamente refinado é } \\
\text { injetado usando a } \\
\text { técnica } \\
\text { microgotículas }\end{array}$ & $\begin{array}{lr}\text { Substituição } & \text { de } \\
\text { volume } & \mathrm{e} \\
\text { contorno } & \end{array}$ & Permanente & $\begin{array}{l}\text { Não pode ser removido } \\
\text { após ser injetado }\end{array}$ & $\begin{array}{l}\text { Cuidado com o silicone não } \\
\text { médico do mercado negro; } \\
\text { uso cosmético off-label (uso } \\
\text { diferente do aprovado em bula } \\
\text { ou ao uso de produto não } \\
\text { registrado no órgão } \\
\text { regulatório de vigilância } \\
\text { sanitária) }\end{array}$ \\
\hline $\begin{array}{l}\text { Polimetilmetacrilato } \\
\text { (PMMA; Artecoll e } \\
\text { Artefill) }\end{array}$ & $\begin{array}{l}\text { Microesferas de } \\
\text { PMMA rodeadas por } \\
\text { colágeno }\end{array}$ & $\begin{array}{l}\text { Aprovado } \\
\text { FDA pela } \\
\text { dobras } \\
\text { nasolabiais, } \\
\text { rugas profundas }\end{array}$ & Permanente & $\begin{array}{lr}\text { Numerosas } & \text { injeções } \\
\text { necessárias } & \text { para o } \\
\text { volume; } & \text { reações } \\
\text { alérgicas } & \text { possíveis; } \\
\text { requer } 3 \text { meses para } \\
\text { efeitos completos; às } \\
\text { vezes visível sob a pele }\end{array}$ & $\begin{array}{l}\text { Por causa do componente de } \\
\text { colágeno bovino, o teste } \\
\text { cutâneo de alergia é } \\
\text { necessário; PMMA não se } \\
\text { decompõe }\end{array}$ \\
\hline $\begin{array}{l}\text { Ácido hialurônico } \\
\text { (Restylane Perlane, } \\
\text { Juvederm, Captique) }\end{array}$ & $\begin{array}{l}\text { Ácido hialurônico de } \\
\text { origem não animal } \\
\text { projetado para resistir } \\
\text { à degradação para } \\
\text { preenchimento r de } \\
\text { rugas e reposição de } \\
\text { volume }\end{array}$ & $\begin{array}{l}\text { Volume } \\
\text { contorno } \\
\text { (periorbital, } \\
\text { nasolabial, } \\
\text { lábios, } \\
\text { bochechas, etc.) }\end{array}$ & $\begin{array}{l}\text { Os resultados } \\
\text { são } \\
\text { e dumediatos } \\
18 \text { meses; } \\
\text { reversível }\end{array}$ & $\begin{array}{l}\text { Pode ser visível ou } \\
\text { palpado se injetado } \\
\text { superficialmente; } \\
\text { menos eficaz para o } \\
\text { tratamento de } \\
\text { lipoatrofia ou correção } \\
\text { de volume muito grande }\end{array}$ & $\begin{array}{l}\text { Estimula nova formação de } \\
\text { colágeno; aprovado pela FDA } \\
\text { para preencher rugas } \\
\text { moderadas a graves ao redor } \\
\text { do nariz e da boca; todos os } \\
\text { outros usos são considerados } \\
\text { off-label; nenhum risco de } \\
\text { transmissão de doenças de } \\
\text { origem animal }\end{array}$ \\
\hline
\end{tabular}

Fonte: Dayan e Bassichis (2008).

Portanto, a análise da Tabela 1 apresenta a comparação entre os preenchedores facial silicone, PMMA e AH, pode-se perceber que o $\mathrm{AH}$ apresenta resultado imediato e tem a propriedade única de ser reversível, destacando-se entre os demais.

Contrariamente ao que se afirma na Tabela 1, ao dizer que produtos de colágeno bovino normalmente duram cerca de 3 meses, segundo Melo et. al. (2018) há relatos de colágeno bovino com duração de até 18 meses.

É bem-sabido que o uso de substâncias de preenchimento, mesmo aquelas aprovadas pela FDA, pode gerar complicações precoces ou tardias, reversíveis ou irreversíveis, com amplo espectro que inclui celulite, equimoses, reações de hipersensibilidade, edema, massa palpável ou visível, granulomas, dermatopatias, abscessos, fístulas, necrose e até cegueira (Díaz, 2019).

O exame de ultrassom é essencial para minimizar os riscos, mas também para localizar e identificar preenchimentos em pacientes com efeitos colaterais (Schelke, Decates \& Velthuis, 2018).

Assim sendo, o ultrassom tem se mostrado um teste rápido, econômico e altamente eficaz para detecção dos diferentes tipos de materiais exógenos, o que também possibilita identificar o grau de absorção de substâncias como o ácido hialurônico e orientar com precisão a injeção de hialuronidase, quando exigido. Por meio do ultrassom é possível reconhecer com precisão o tipo de substância injetada, uma vez que cada uma delas apresenta um aspecto ultrassonográfico característico que permite estabelecer com precisão de qual material de preenchimento se trata (Díaz, 2019).

Não apenas o ácido hialurônico, mas também todos os preenchimentos são visíveis ao ultrassom. Os pacientes que fizeram tratamentos anteriores com preenchimento nem sempre se lembram do tipo de preenchimento, do local e do plano de injeção. No entanto, diferentes substâncias de preenchimento podem causar efeitos colaterais indesejados, quando misturadas (Schelke, Decates \& Velthuis, 2018).

Com o exame de ultrassom/duplex, a pele e o tecido subjacente, incluindo músculos, veias e artérias, podem se tornar visíveis. Ao mesmo tempo, qualquer enchimento pode ser visto, medido em tamanho e o plano de injeção pode ser visto. 
Percebeu-se que o uso de duplex fornece uma melhoria importante na segurança dos tratamentos de preenchimento dérmico (Schelke, Decates \& Velthuis, 2018).

Os autores aqui apesentados são unânimes em considerar o exame de ultrassom como uma técnica primordial para a aplicação de preenchedores faciais, como também, constitui a ferramenta indispensável para tratar efeitos danosos à face em decorrência de complicações.

\section{Conclusão}

A partir do estudo de caso, pode-se constatar como o exame de ultrassonografia é imprescindível para o trabalho com preenchedores faciais, porque serve como um método de precisão para investigar e tratar complicações ou resolver dúvidas. O caso da paciente L. T. T. mostra que após o preenchimento facial, na região do mento, a paciente trouxe uma queixa que foi elucidada pelo exame de ultrassonografia, que funcionou como uma técnica de rastreamento.

O ácido hialurônico, como visto nas discussões, tem como característica não migrar de seu local, portanto, não se esperava seu deslizamento para a região submentoniana. Entendeu-se do caso clínico a importância de que o profissional, que trabalha com harmonização facial, conheça bem todos os preenchedores.

Sugere-se que os pesquisadores da ciência Odontológica investiguem a fundo as relações entre os preenchedores faciais e tratamentos odontológicos, uma vez que a ultrassonografia é o único recurso, indispensável, para avaliar e tratar quaisquer danos da harmonização facial.

\section{Referências}

Al Ramzi, A., Kassim, M., George, J. V., \& Amin, A. (2015). Dental procedures: is it a risk factor for injectable dermal fillers? Journal of maxillofacial and oral surgery, 14(1), 158-160. https://doi.org/10.1007/s12663-012-0398-y

Attenello, N. H., Maas, C. S. (2015). Facial Plast Surg. Feb; 31(1):29-34. https://doi.org/10.1055/s-0035-1544924

Badin, A. Z. D. (2005). Cirurgia da face e procedimentos ancilares. Cirurgia plástica. São Paulo: Atheneu, 521-33. http://www.rbcp.org.br/export-pdf/447/2401-13.pdf

Bertossi Dario, MD; Irene Dell'Acqua, MD; Massimo Albanese, MD; Pierpaolo Marchetti, PhD; e Pierfrancesco Nocini, MD. (2019). Tratamento de Rosto Usando técnicas Nonsurgical Mini-invasivos como pós-cirúrgica Procedimento para lesão traumática. Sociedade Americana de Cirurgia Plástica Estética.10, 37134. http://openrit.grupotiradentes.com:8080/xmlui/handle/set/3482

Brasil. (2018). Agência Nacional de Vigilância Sanitária - Anvisa. Procedimento estético: anvisa esclarece sobre indicações do PMMA. Ministério da Saúde, on-line. https://www.gov.br/anvisa/pt-br/assuntos/noticias-anvisa/2018/anvisa-esclarece-sobre-indicacoes-do-pmma

Carruthers, Carruthers J. (2016). Considerações científicos e técnicos: A base de não animais. Plast Reconstr Surg. 120: 33S-40S. http://openrit.grupotiradentes.com:8080/xmlui/handle/set/3482

Crocco, E. I., Alves, R. O., \& Alessi, C. (2012). Eventos adversos do ácido hialurônico injetável. Surgical \& Cosmetic Dermatology, 4(3), 259-263. https://www.redalyc.org/pdf/2655/265524650007.pdf

Dalati, M. H. N., \& Koussayer, L. T. (2020). An Introduction to Botulinum Toxin and Dermal Fillers for Dentists: Part 1. EC Dental Science, 19 , 142-157. https://www.researchgate.net/profile/Hani-Dalati/publication/302484818_Botox_and_dermal_fillers_use_in_dentistry/links/5f32d99092851cd302ef2 0fb/Boto $\mathrm{x}$-and -de rmal-fillers-use-in-dentistry.pdf

Dayan, S. H., \& Bassichis, B. A. (2008). Facial dermal fillers: selection of appropriate products and techniques. Aesthetic surgery journal, 28(3), 335-347. https://doi.org/10.1016/j.asj.2008.03.004

Díaz, C. P. G. (2019). High resolution ultrasound of soft tissues for characterization of fillers and its complications. Revista Colombiana de Radiologica, 30, 5064-5068. https://www.webcir.org/revistavirtual/articulos/2019/2_mayo/colrad/ecog_esp.pdf

Dolghi, S. M. (2014). Avaliação de implantes de polimetilmetacrilato (PMMA) para procedimentos de bioplastia. http://dspace.sti.ufcg.edu.br:8080/jspui/handle/riufcg/347

Facial, H. (2018). O uso do ácido hialurônico na harmonização facial: uma breve revisão. https://www.mastereditora.com.br/periodico/20180704_092807.pdf

Gladstone HB, Cohen JL. (2007). Os efeitos adversos quando se injeta enchimentos faciais. doença semi Med Surg. 26(1):34-39. http://openrit.grupotiradentes.com:8080/xmlui/handle/set/3482 
Goodman, G. J., Liew, S., Callan, P., \& Hart, S. (2020). Facial aesthetic injections in clinical practice: Pretreatment and posttreatment consensus recommendations to minimise adverse outcomes. Australasian Journal of Dermatology, 61(3), 217-225. https://doi.org/10.1111/ajd.13273

Hexsel, D.; Morais, M. R. (2014). Management of Complications of Injectable Silicone. December Facial Plastic Surgery 30(6):623-7. https://books.google.com.br/books?hl=pt-

BR\&lr=\&id=YNuZCwAAQBAJ\&oi=fnd\&pg=PP1\&dq=Hexsel, +D.\%3B+Morais, + M. + R. $+(2014) .+$ Management + of + Complications + of + Injectable + Silicone. + December+Facial+Plastic+Surgery+30(6):623-7.+\&ots=QAKcZEzEDi\&sig=vjPFVMDeBcixmQtYqXPoZ7uq13I\#v=onepage\&q\&f=false

Junkins-Hopkins, J. M. (2015). Filler complications. J Am Acad Dermatol., v. 63, n. 4, p. 703-5. https://doi.org/10.4081/dr.2015.5851

Limongi, R. M., Tao, J., Borba, A., Pereira, F., Pimentel, A. R., Akaishi, P., \& Velasco e Cruz, A. A. (2016). Complications and management of polymethylmethacrylate (PMMA) injections to the midface. Aesthetic surgery journal, $36(2)$, 132-135. https://academic.oup.com/asj/article/36/2/132/2589288?login=true

Monteiro, É. (2010). Envelhecimento facial: perda de volume e reposição com ácido hialurônico. $R$ BM rev. bras. med. https://biblat.unam.mx/pt/revista/rbmrevista-brasileira-de-medicina/articulo/envelhecimento-facial-perda-de-volume-e-reposicao-com-acido-hialuronico

Moraes, B. R. D., Bonami, J. A., Romualdo, L., Comune, A. C., \& Sanches, R. A. (2017). Ácido hialurônico dentro da área de estética e cosmética. Saúde Foco, 9, 552-562. http://docplayer.com.br/67670744-Acido-hialuronico-dentro-da-area-de-estetica-e-cosmetica.html

Parada, M. B., Cazerta, C., Afonso, J. P. J. M., \& do Nascimento, D. I. S. (2016). Manejo de complicações de preenchedores dérmicos. Surgical \& Cosmetic Dermatology, 8(4), 342-351. https://www.redalyc.org/pdf/2655/265549460019.pdf

Pérez-Pérez, L., García-Gavín, J., Wortsman, X., \& Santos-Briz, Á. (2017). Delayed adverse subcutaneous reaction to a new family of hyaluronic acid dermal fillers with clinical, ultrasound, and histologic correlation. Dermatologic Surgery, 43(4), 605-608. https://doi.org/10.1097/DSS.0000000000000945

Requena, L., Requena, C., Christensen, L., Zimmermann, U. S., Kutzner, H., \& Cerroni, L. (2011). Adverse reactions to injectable soft tissue fillers. Journal of the American Academy of Dermatology, 64(1), 1-34. https://doi.org/10.1016/j.jaad.2010.02.064

Rocha, L. P. C., de Carvalho Rocha, T., Rocha, S. D. C. C., Henrique, P. V., Manzi, F. R., \& e Silva, M. R. M. A. (2020). Ultrasonography for long-term evaluation of hyaluronic acid filler in the face: A technical report of 180 days of follow-up. Imaging Science in Dentistry, 50(2), 175 . https://doi.org/10.5624/isd.2020.50.2.175

Sattler, G., Gout, U. (2017). Guia ilustrado para preenchimentos injetáveis: bases, indicações, tratamentos. 1. ed. São Paulo: Quintessence editora. https://www.dilivros.com.br/livro-guia-ilustrado-para-preenchimentos-injetaveis--base-indicacoes-tratamento-9788578890858,s25353.html

Schelke, LW., Decates, TS., Velthuis PJ. (2018). Ultra-som para melhorar a segurança dos tratamentos de preenchimento de ácido hialurônico. J Cosmet Dermatol. Dezembro; 17 (6): 1019-1024 https://doi.org/10.1111/jocd.12726

Signorini, M., Liew, S., Sundaram, H., De Boulle, KL., Goodman, GJ., Monheit, G., Wu, Y., Trindade de Almeida, AR., Swift, A., Vieira Braz, A. (2016). Global Aesthetics Consensus Group. Plast Reconstr Surg. Jun; 137(6):961e-971e. https://doi.org/ 10.1097/PRS.0000000000002184

Souza, T. A. B., Colomé, L. M., Bender, E. A., \& Lemperle, G. (2018). Brazilian consensus recommendation on the use of polymethylmethacrylate filler in facial and corporal aesthetics. Aesthetic plastic surgery, 42(5), 1244-1251. https://doi.org/10.1007/s00266-018-1167-1

Vargas, A. F., Amorim, N. G. D., \& Pintanguy, I. (2009). Complicações tardias dos preenchimentos permanentes. Rev. bras. cir. plást, 71-81. http://www.rbcp.org.br/export-pdf/447/24-01-13.pdf.

Wortsman, X., Wortsman, J., Orlandi, C., Cardenas, G., Sazunic, I., \& Jemec, G. B. E. (2012). Ultrasound detection and identification of cosmetic fillers in the skin. Journal of the European Academy of Dermatology and Venereology, 26(3), 292-301. https://doi.org/10.1111/j.1468-3083.2011.04047.x 